\title{
Cerebrolysin in Mild-to-Moderate Alzheimer's Disease: A Meta-Analysis of Randomized Controlled Clinical Trials
}

\author{
Serge Gauthier ${ }^{a} \quad$ Jefferson Voltaire Proaño ${ }^{b}$ Jianping Jia ${ }^{c}$ Lutz Froelich ${ }^{d}$ \\ Johannes Christophe Vester ${ }^{\mathrm{e}}$ Edith Doppler ${ }^{\mathrm{f}}$ \\ ${ }^{a}$ McGill Center for Studies in Aging, Montreal, Que., Canada; ${ }^{b}$ National Disease Medical \\ Research Unit, Instituto Mexicano del Seguro Social, Tlacotalpan, México; ' Department of \\ Neurology, Xuan Wu Hospital of the Capital Medical University, Beijing, China; ${ }^{d}$ Department of \\ Geriatric Psychiatry, Central Institute of Mental Health, Medical Faculty Mannheim, \\ University of Heidelberg, Mannheim, and eidv Data Analysis and Study Planning, \\ Department of Biometry and Clinical Research, Krailling, Germany; ${ }^{{ } E V E R}$ Neuro Pharma \\ $\mathrm{GmbH}$, Unterach, Austria
}

\author{
Key Words \\ Cerebrolysin · Mild-to-moderate Alzheimer's disease $\cdot$ Randomized controlled clinical \\ trials · Brain · Drug therapy · Geriatrics · Mental disorders · Neurology · Nervous system · \\ Pharmacology $\cdot$ Therapeutics
}

\begin{abstract}
Objective: The aim of this study was to provide a systematic and quantitative summary of benefit and risk of Cerebrolysin in patients with mild-to-moderate Alzheimer's disease (AD) and to avoid major deficiencies of an earlier meta-analysis. Design: This is a meta-analysis of randomized double-blind placebo-controlled clinical trials. Data Sources: Trials were identified with the help of PubMed, the Cochrane Dementia Group database, the Center for Collaborative Neurosciences, and references from reviews; no language restrictions were applied. Study Selection: All randomized double-blind placebo-controlled studies on $30 \mathrm{ml} /$ day of Cerebrolysin in mild-to-moderate AD were included. Results: There were 6 eligible randomized controlled trials comparing Cerebrolysin with placebo. For all studies, either individual patient data and/or published data (aggregate data) were available. Analyses were based on the odds ratio $(O R)$ for dichotomized global clinical change and for safety criteria, on the standardized mean difference (SMD) for pooling of cognitive function, and on the Mann-Whitney statistic (MW) for multivariate analysis of 'global benefit' (combined effect of global clinical change and cognitive function). Cerebrolysin was significantly more effective than placebo at 4 weeks regarding cognitive function ( 4 weeks: SMD -0.40 points; $95 \%$ CI -0.66 to $-0.13 ; p=$ $0.0031 ; 6$ months: SMD -0.37 points; $95 \%$ CI -0.90 to $0.16 ; p=0.1710$ ), at 4 weeks and 6 months regarding global clinical change (4 weeks: OR 3.32; $95 \%$ CI $1.20-9.21 ; p=0.0212 ; 6$
\end{abstract}


months: OR 4.98; 95\% CI 1.37-18.13; $p=0.0150)$, and at 4 weeks and 6 months regarding 'global benefit' (combined efficacy criteria; 4 weeks: MW 0.57, 95\% CI 0.53-0.61; $p=0.0006$; 6 months: MW 0.57; 95\% CI 0.53-0.61; $\mathrm{p}=0.0010$ ). The safety aspects of Cerebrolysin were comparable to placebo. Conclusion: This meta-analysis provides evidence that Cerebrolysin has an overall beneficial effect and a favorable benefit-risk ratio in patients with mild-to-moderate AD. Cerebrolysin as a therapeutic agent should be considered by clinicians seeking treatment options for mild-to-moderate $A D$.

(C) 2015 S. Karger AG, Base

\section{Introduction}

Cerebrolysin is a parenterally administered neuropeptide preparation with pharmacodynamic properties similar to those of endogenous neurotrophic factors [1]. Treatment with Cerebrolysin improved cognitive, global, and functional domains in mild-to-moderately severe stages of dementia due to Alzheimer's disease (AD) as well as to vascular dementia. However, there is still insufficient evidence to recommend Cerebrolysin as a routine treatment for vascular dementia or AD. Efficacy outcomes and safety data from randomized placebocontrolled clinical trials in mild-to-moderate stages of AD have been reviewed by Plosker and Gauthier [2]. The current review is based on a systematic meta-analysis of randomized controlled trials (RCTs) using Cerebrolysin compound. The need for such a review is to have a fresh look at a pharmacological alternative to amyloid-targeting compounds which have failed so far to significantly impact patients' care.

\section{Methods}

\section{Identification of Studies and Collection of Data}

Trials were included in this review only if they were randomized, double blind, and placebo controlled. Trials were identified from the Cochrane Dementia Group database of trials by searching for the term 'Cerebrolysin', from PubMed using the search terms 'Cerebrolysin' and 'Alzheimer', from a large Cerebrolysin review by the Center for Collaborative Neurosciences [3], as well as from the sponsor's own list of Cerebrolysin studies. It is interesting to note that the Cochrane Dementia and Cognitive Improvement Group announced a review of 'Cerebrolysin for Alzheimer's Disease' in 2002, with amendment in 2008 [4]; however, no results have been published up to now.

For all randomized double-blind placebo-controlled studies, published data were available; thus, no study had to be excluded from meta-analysis. In addition to aggregate data from publications, for 3 studies [5-7], raw data were available for individual patient data (IPD) analyses. In this way, a combination of all studies by means of a mixed meta-analysis approach was possible integrating results from IPD reanalyses as well as from aggregate data from publications. Thus, the broadest possible summary of clinical efficacy results could be reached. Compared to pure 'aggregate data' meta-analyses, the mixed approach assures a higher level of validity and is recommended by leading researchers wherever feasible [8].

\section{Statistical Analysis}

\section{Handling of Original Outcomes Scales}

The included studies assessed outcome using a variety of measures, such as: Alzheimer's Disease Assessment Scale - cognitive subscale (ADAS-cog) [9], ADAS-cog+ (extension of ADAS-cog with 3 additional items) [10], Mini-Mental State Examination (MMSE) [11], Trail-Making Test (Zahlen-Verbindungs-Test, gerontopsychological version; ZVT-G) [12], Clinician Interview-Based Impression of Change with Caregiver Input (CIBIC+) [13], or Clinical Global Impression (CGI) [14]. 
Table 1. Primary outcome measures in single studies

\begin{tabular}{l|l}
\hline Dement Geriatr Cogn Disord 2015;39:332-347 \\
\hline DOI: 10.1159/000377672 & $\begin{array}{l}\text { @ 2015 S. Karger AG, Basel } \\
\text { www.karger.com/dem }\end{array}$ \\
\hline
\end{tabular}

Gauthier et al.: Cerebrolysin in Mild-to-Moderate Alzheimer's Disease: A Meta-Analysis of Randomized Controlled Clinical Trials

\begin{tabular}{llllll}
\hline Study & $\begin{array}{l}\text { ADAS- } \\
\text { cog+ }+^{\mathrm{a}}\end{array}$ & $\begin{array}{l}\text { ADAS- } \\
\operatorname{cog}^{\mathrm{b}}\end{array}$ & & & \\
\hline Alvarez et al. [5] & $\mathrm{x}$ & & $\mathrm{x}$ & & \\
Panisset et al. [6] & & $\mathrm{x}$ & $\mathrm{x}$ & & \\
$\begin{array}{l}\text { Ruether et al. [7] } \\
\text { Ruether et al. [15] }\end{array}$ & $\mathrm{x}$ & & $\mathrm{x}$ & & \\
Bae et al. [16] & $\mathrm{x}$ & & $\mathrm{x}$ & & $\mathrm{x}$ \\
Xiao et al. [17] & & & $\mathrm{x}$ & $\mathrm{x}$ & \\
\hline
\end{tabular}

${ }^{\text {a }}$ ADAS-cog modified, 14 items. ${ }^{\text {b }}$ ADAS-cog, 11 items. ${ }^{\mathrm{c}}$ CGI, item 2.

The original primary outcome measures of the 6 studies are displayed in table 1 . In order to allow comparison across studies, the outcome scales of the individual studies (table 1) were standardized as follows:

Global Clinical Change

For scales assessing the global clinical change (CIBIC+ and CGI), a dichotomization was performed according to the proposals of the Cochrane Collaboration (improvement vs. unchanged/worse), thus allowing the combination of studies with CIBIC+ and CGI. The effect size used for the evaluation of the dichotomized outcome scales is the odds ratio (OR).

Cognitive Function

In order to compensate for the different primary cognitive outcome measures (ADAS-cog, ADAS-cog+, MMSE, and ZVT), the scales were standardized using the standardized mean difference (SMD) approach. This is a common Cochrane methodology for handling of different outcome scales in the same domain, allowing the combination of results based on means, independent of any specific scale, and also allowing comparison with published SMD results of previous meta-analyses performed by other authors (regarding the use of SMDs for meta-analyses of cognitive scales, see the recommendations of the Cochrane Collaboration $[18,19]$ and IQWIG [20]).

In all individual RCTs, the primary evaluation of the cognitive scales was defined as 'change from baseline'. Thus, in the formal meta-analyses the 'change from baseline' values were used as a base for the calculation of the SMDs.

Global Benefit (Combined Effect of Global Clinical Change and Cognitive Function)

A formal combination of clinical global change and cognitive function, which are the two major domains in AD outcome as suggested by the FDA [21], provides a useful summarizing measure for 'global benefit'. The corresponding analysis was performed applying the Wei-Lachin procedure $[15,16]$, a multivariate generalization of the Wilcoxon-Mann-Whitney test, which produces an overall average estimate of benefit and test for treatment differences. Please note that the chosen procedure is not based on a 'composite' endpoint, but on a multivariate approach taking account of the correlations among the included endpoints. This preplanned meta-analysis of global benefit was based on a multivariate reanalysis of the 3 studies [5-7] with available raw data (IPD studies), since IPD are required for this nonparametric procedure.

The procedure is described by Wei and Lachin [22] and Lachin [23]. Practical examples are given in modern textbooks on multiple testing problems (see e.g. Dmitrienko et al. [24]).

It is important to note that the multivariate directional test procedure chosen for this study can cope simultaneously with binary, ordinal, and continuous data. Thus, there is no technical need for the widely used dichotomization of original scales which is associated with substantial loss of information and reflects a major disadvantage of previous AD studies. The corresponding global effect size measure is the MannWhitney statistic (for description and common benchmarks, see Results section).

Handling of Safety Aspects

Premature discontinuation, premature discontinuation due to an adverse event (AE), and patients with at least 1 treatment-emergent AE (TEAE) were analyzed based on OR. 
Gauthier et al.: Cerebrolysin in Mild-to-Moderate Alzheimer's Disease: A Meta-Analysis of Randomized Controlled Clinical Trials

Treatment of Missing Values

Some of the analyzed studies used an observed cases (OC) analysis as a primary analysis (which corresponds to a 'completer' analysis at the final point in time), while other studies used the last observation carried forward (LOCF) technique for the replacement of missing values. The OC analysis is regarded by many researchers as the more conservative approach in placebo-controlled studies with progressive diseases. Thus, the meta-analyses reported herein are based on OC analyses. LOCF analyses were conducted in addition as sensitivity analyses.

Points in Time

For all 6 studies, data for the evaluation of short-term results after 4 weeks were available. For the evaluation of the long-term results after 6 months, data from $4[5-7,15]$ out of 6 studies were available (table 2).

\section{Patient Populations}

For all studies, the intention to treat (ITT) population was defined as the primary analysis population in the original investigational plans (with either LOCF or OC treatment of missing values). Thus, the original ITT population was also used as the basic patient population for the formal meta-analyses.

Method of Synthesis

The formal meta-analyses reported herein used the following effect size measures and their associated two-sided 95\% CI as described above:

- $\quad$ OR for dichotomized global clinical change and for safety criteria (equality: OR = 1.0; superiority: OR > 1.0)

- $\quad$ SMD for pooling of primary cognitive scales (Hedges' g; equality: SMD = 0.0; superiority: SMD < 0.0)

- Mann-Whitney statistic (MW) for multivariate analysis of 'global benefit' (equality: MW= 0.5; superiority: MW > 0.5)

In addition to the above effect sizes, the number needed to treat (NNT) was calculated. The NNT is the number of patients who must be treated to generate 1 more success or 1 less failure than would have resulted if all patients had been given the comparator treatment. Mathematically, the NNT is the reciprocal of the risk difference. The measure was proposed for clinical interpretation of risk differences (sometimes called absolute risk reduction) by Laupacis et al. [25]. The effect size NNT was recommended, beginning in the late 1990s, by several authors (Cook and Sackett [26] in 1995, Altman [27] in 1998, Guyatt et al. [28] in 1998, Walter [29] in 2001, and Altman and Andersen [30] in 1999). The NNT measure has gained wide popularity among clinical researchers and is also recommended by the revised CONSORT statement [31, 32].

For all effect sizes, overall estimates of the treatment difference were calculated. Tests for quantitative heterogeneity were performed using standard $\chi^{2}$ statistic and $\mathrm{I}^{2}$ statistic. Qualitative interaction was tested by means of the Gail-Simon test [33]. If there was no evidence for qualitative or quantitative interaction, the fixed-effects model was interpreted. If, however, there was evidence of heterogeneity of the treatment effect between trials $\left(\mathrm{p}<0.1 ; \mathrm{I}^{2}>50 \%\right.$ ), then a random-effects model was used for interpretation (DerSimonianLaird) [34].

\section{Results}

\section{Study Population}

There were 6 eligible RCTs comparing $30 \mathrm{ml} /$ day of Cerebrolysin with placebo (table 2). For all studies, either IPD and/or published data (aggregate data) were available. With respect to the primary cognitive assessments, this resulted in available data for month 1 on 763 (97.3\%) of a total of 784 ITT patients and for month 6 on 519 (90.4\%) of a total of 574 ITT patients (studies with a 6-month observational period). Regarding global clinical change, this resulted in available data for month 1 on 780 (99.5\%) of a total of 784 ITT patients and for month 6 on 525 (91.5\%) of a total of 574 ITT patients (studies with a 6-month observational period). Thus, at all points in time, the number of missing observations was below $10 \%$, i.e. within the range recommended for class I evidence-based quality studies [20,35]. The characteristics of the included studies are described in tables 2 and 3. While all studies had 20 

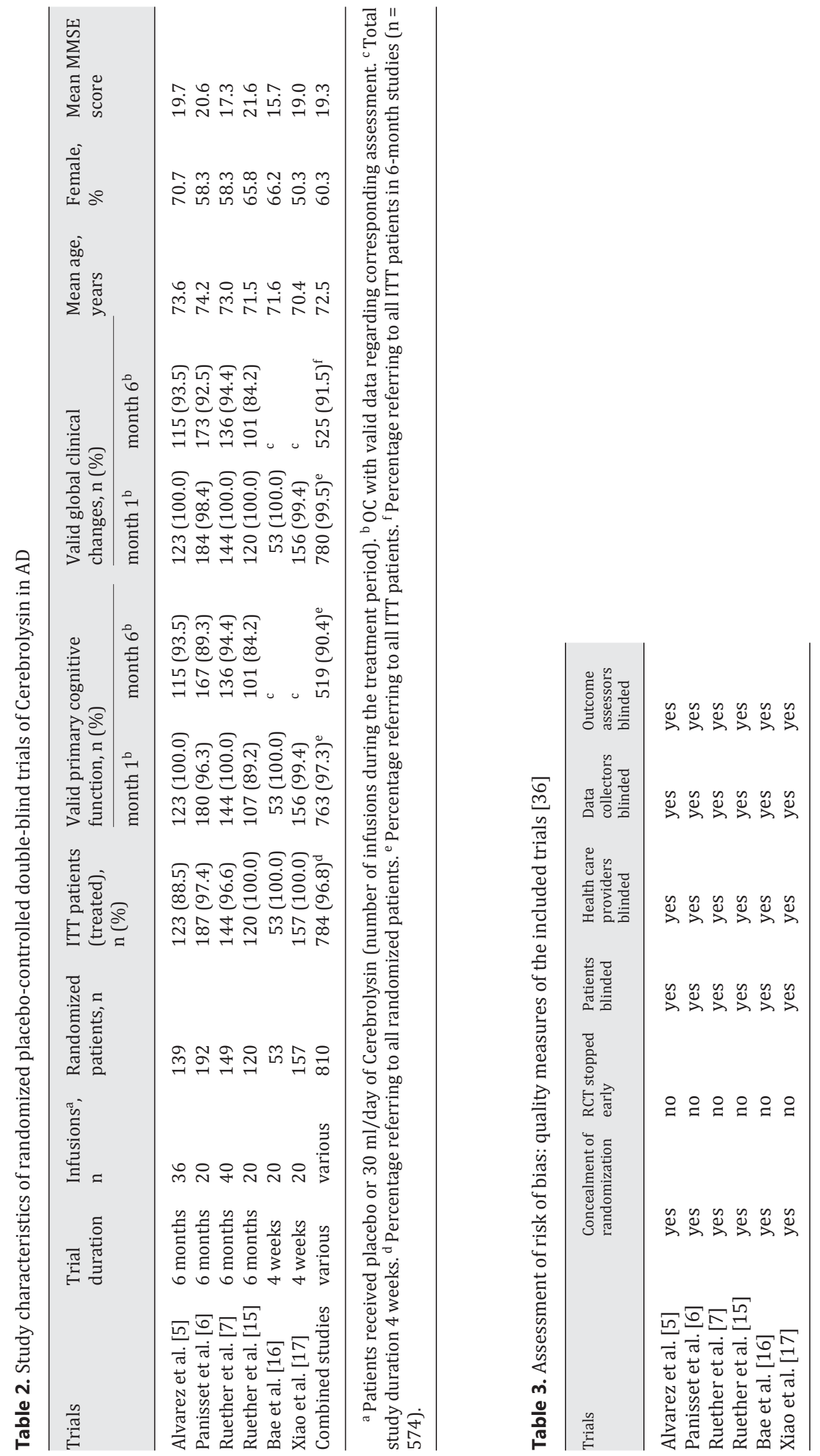


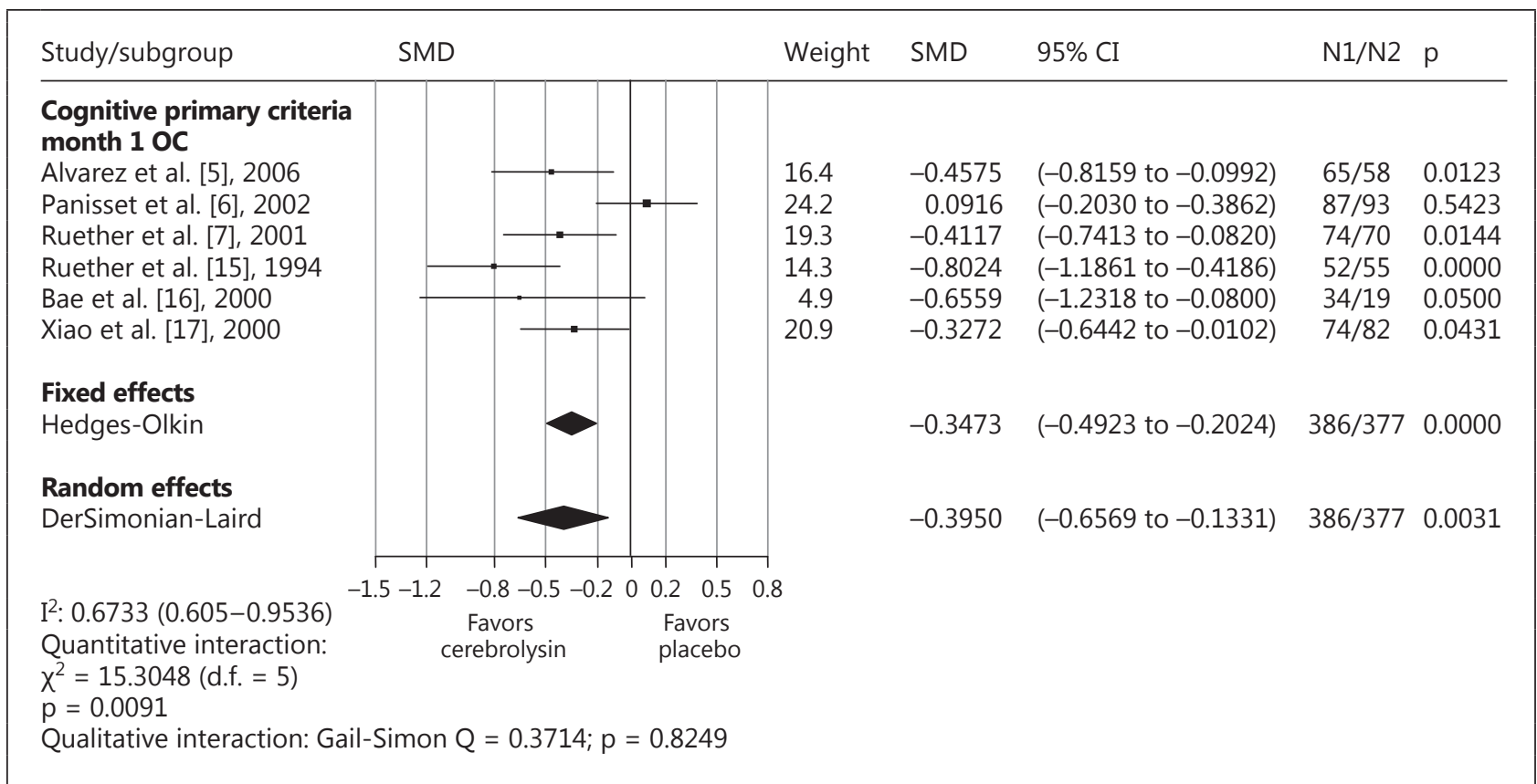

Fig. 1. Comparison of Cerebrolysin (30 ml/day) versus placebo at week 4, primary cognitive outcome measures, changes from baseline, effect size: SMD, OC.

infusions during the first 4 weeks with $30 \mathrm{ml}$ of Cerebrolysin per day, in 1 study [7] an additional treatment cycle of 20 infusions after a treatment-free interval of 8 weeks was introduced, and in 1 study [5] treatment was continued after 4 weeks with 2 infusions per week for another treatment period of 8 weeks. The mean age of the patients varied between 70.4 and 74.2 years, the proportion of females was between 50.3 and $70.7 \%$, and the average MMSE score varied between 15.7 [16] and 21.6 [15].

\section{Cognitive Function}

The OC analysis, based on 6 studies, showed that for primary cognitive efficacy criteria at 4 weeks, there was a -0.40 -point ( $95 \% \mathrm{CI}-0.66$ to $-0.13 ; \mathrm{p}=0.0031)$ difference in favor of Cerebrolysin relative to placebo (SMD, OC analysis; fig. 1). The analysis at 6 months, based on 4 studies, revealed a comparable difference of -0.37 points ( $95 \% \mathrm{CI}-0.90$ to $0.16 ; \mathrm{p}=0.1710$ ), again favoring Cerebrolysin, however, missing statistical significance (fig. 2). Random-effects models were used for all of these analyses. At both points in time, there was no evidence of qualitative interaction $\left(\mathrm{p}_{\text {Gail-Simon }}>0.2\right)$; however, there was evidence of quantitative interaction $\left(\mathrm{p}<0.1 ; \mathrm{I}^{2}>50 \%\right)$.

\section{Global Clinical Change}

The CGI and CIBIC+ are used to provide an overview by the clinician of whether a patient is getting better or worse. Results of the meta-analysis showed an OR for improvement after 4 weeks with Cerebrolysin compared to placebo of 3.32 (95\% CI 1.20-9.21; $p=0.0212$ (fig. 3). The number of patients who need to be treated for 1 patient to benefit (NNT) was estimated to be 3.4 when considering any level of improvement, while the corresponding rate difference was $29.0 \%$ in favor of Cerebrolysin. After 6 months, the OR for improvement was 4.98 (95\% CI 1.37-18.13; $\mathrm{p}=0.0150$; fig. 4). The NNT was estimated to be 2.9 , while the corresponding 


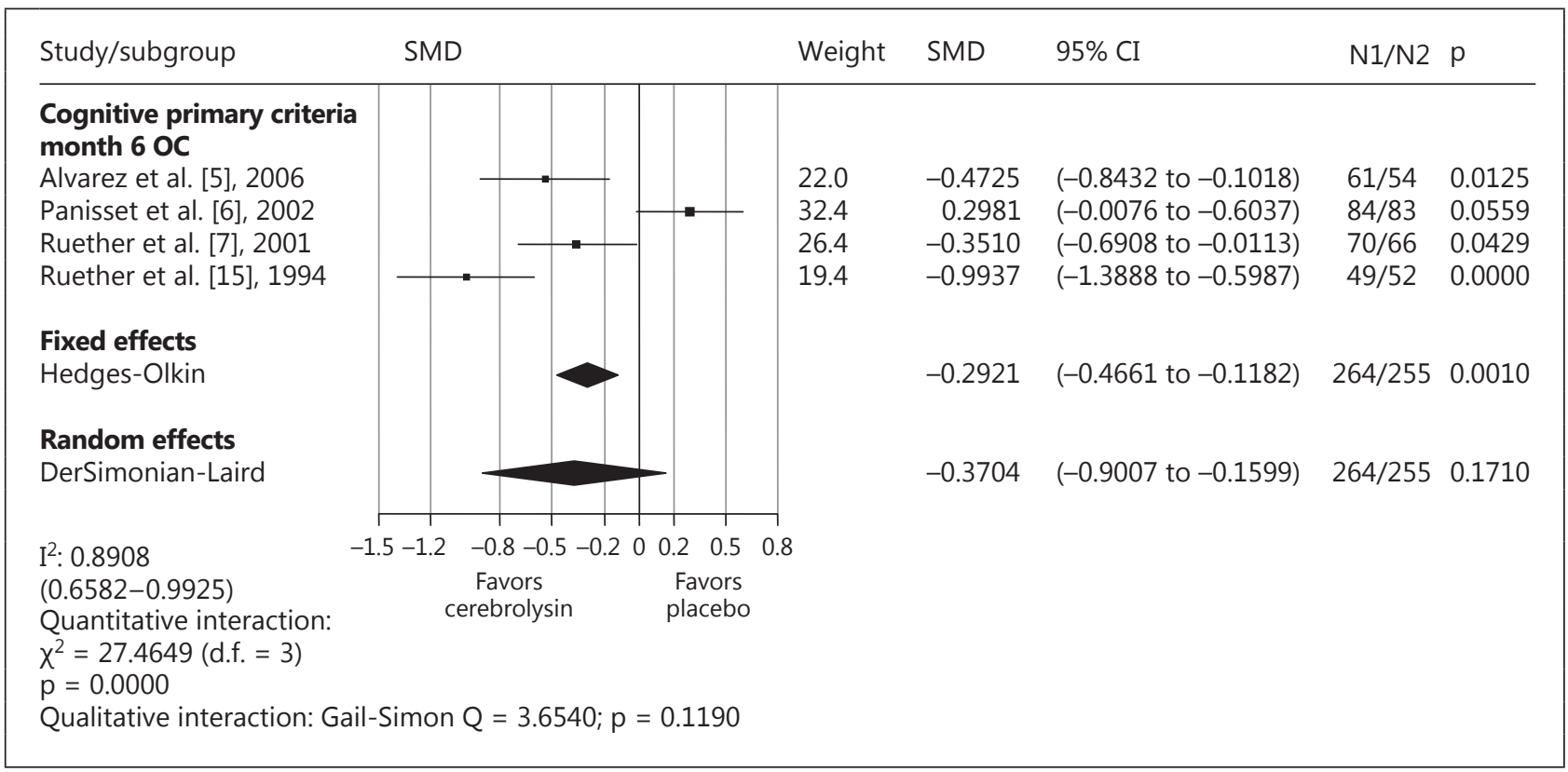

Fig. 2. Comparison of Cerebrolysin ( $30 \mathrm{ml} /$ day) versus placebo at month 6, primary cognitive outcome measures, changes from baseline, effect size: SMD, OC.

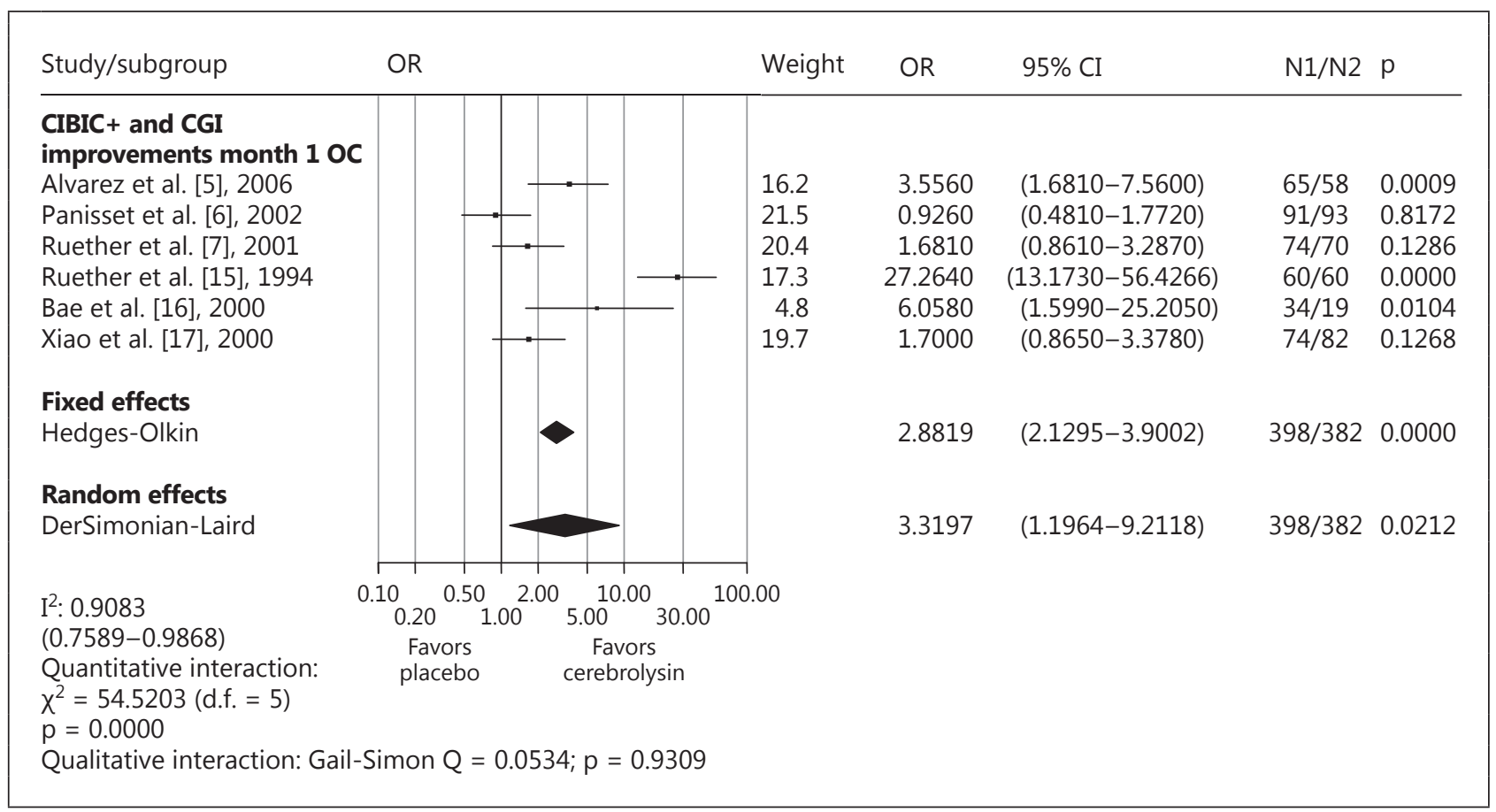

Fig. 3. Comparison of Cerebrolysin ( $30 \mathrm{ml} /$ day) versus placebo at week 4 , global clinical change, effect size: OR, OC. 


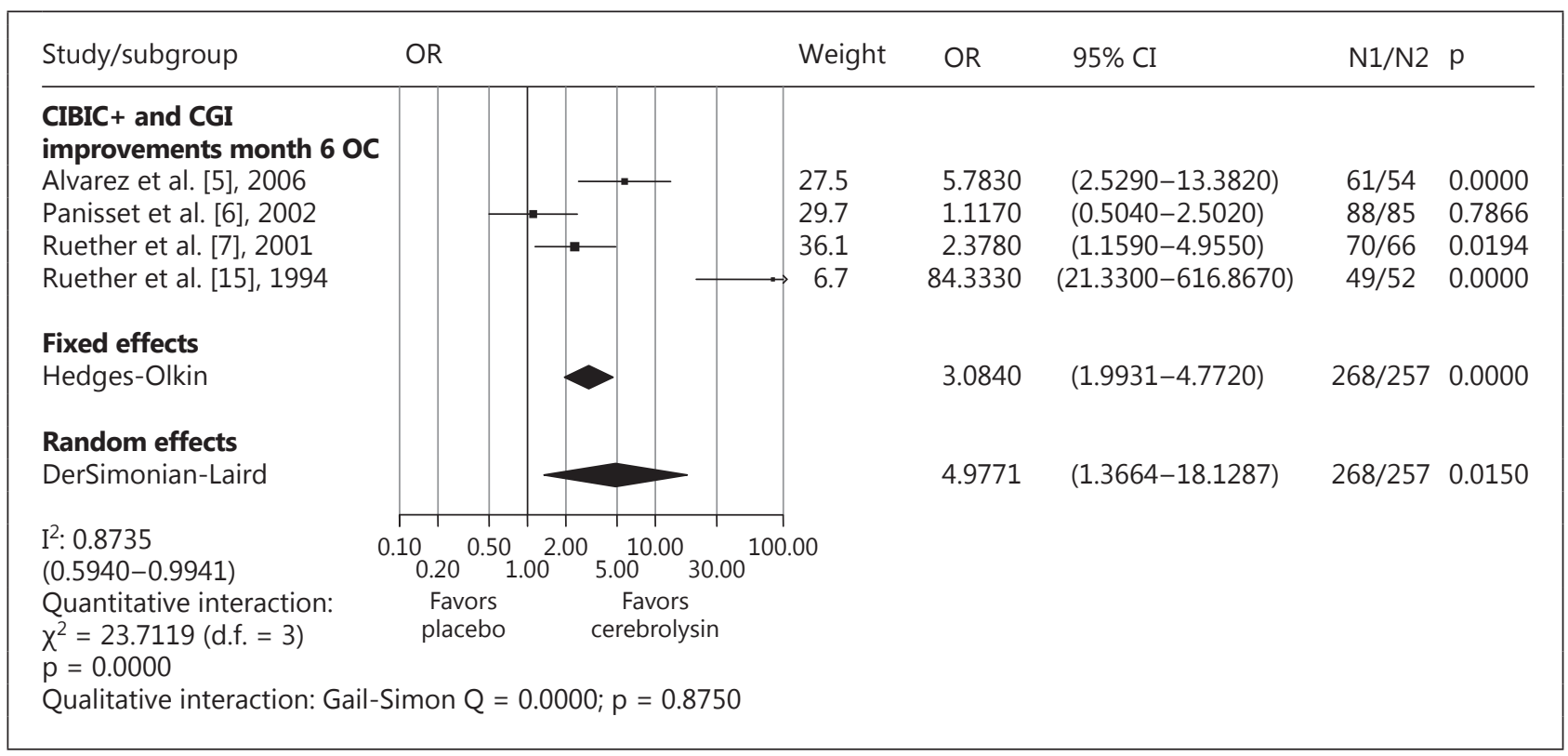

Fig. 4. Comparison of Cerebrolysin ( $30 \mathrm{ml} /$ day) versus placebo at month 6 , global clinical change, effect size: OR, OC.

rate difference was $35.0 \%$ in favor of Cerebrolysin. For all these analyses, random-effects models were used. There was no evidence of qualitative interaction ( $\left.\mathrm{p}_{\text {Gail-Simon }}>0.2\right)$; however, there was substantial quantitative interaction $\left(\mathrm{p}<0.1 ; \mathrm{I}^{2}>50 \%\right)$. An alternatively performed LOCF analysis confirmed the results of the OC analysis.

\section{Global Benefit (Combined Effect of Global Clinical Change and Cognitive Function)}

In addition to the univariate analyses of the two primary domains (global clinical change and cognitive function), these domains were also evaluated applying a unifying multivariate directional test approach (Wei-Lachin procedure as multivariate generalization of the Wilcoxon-Mann-Whitney test), reflecting the overall status of patients with AD at week 4 (short-term analysis) and month 6 (long-term follow-up).

The Mann-Whitney statistic is the most valuable effect size measure for the WilcoxonMann-Whitney test because it is appropriate where the Hodges-Lehmann shift parameter is no longer valid. Furthermore, the Mann-Whitney effect size measure (MW) is appropriate for continuous, ordinal, and binary data at the same time and represents an ideal effect size measure for multiple outcomes. It gives the probability that a randomly chosen patient of the test group is better off than a randomly chosen patient of the comparison group, defined by the statistical shortcut: $\mathrm{p}(\mathrm{X}<\mathrm{Y})+0.5 \mathrm{p}(\mathrm{X}=\mathrm{Y})$.

The traditional benchmarks for the Mann-Whitney effect size measure (MW) are as follows [37]: 0.29 = large inferiority; 0.36 = medium inferiority; $0.44=$ small inferiority; 0.50 = equality; 0.56 = small superiority; $0.64=$ medium superiority, and $0.71=$ large superiority. Figures 5 and 6 show the results of the multivariate analyses (overall status of patients with AD) at week 4 and at month 6. Please note that only studies with available raw data [5-7] are eligible for this multivariate analysis (IPD studies).

As shown in figures 5 and 6, more than a 'small' superiority of Cerebrolysin is shown at week 4 as well as at month 6 with respect to the combined efficacy criterion (MW > 0.57, p = 0.0006 and 0.0010 , respectively; Wei-Lachin pooling [38]). An alternatively performed LOCF 


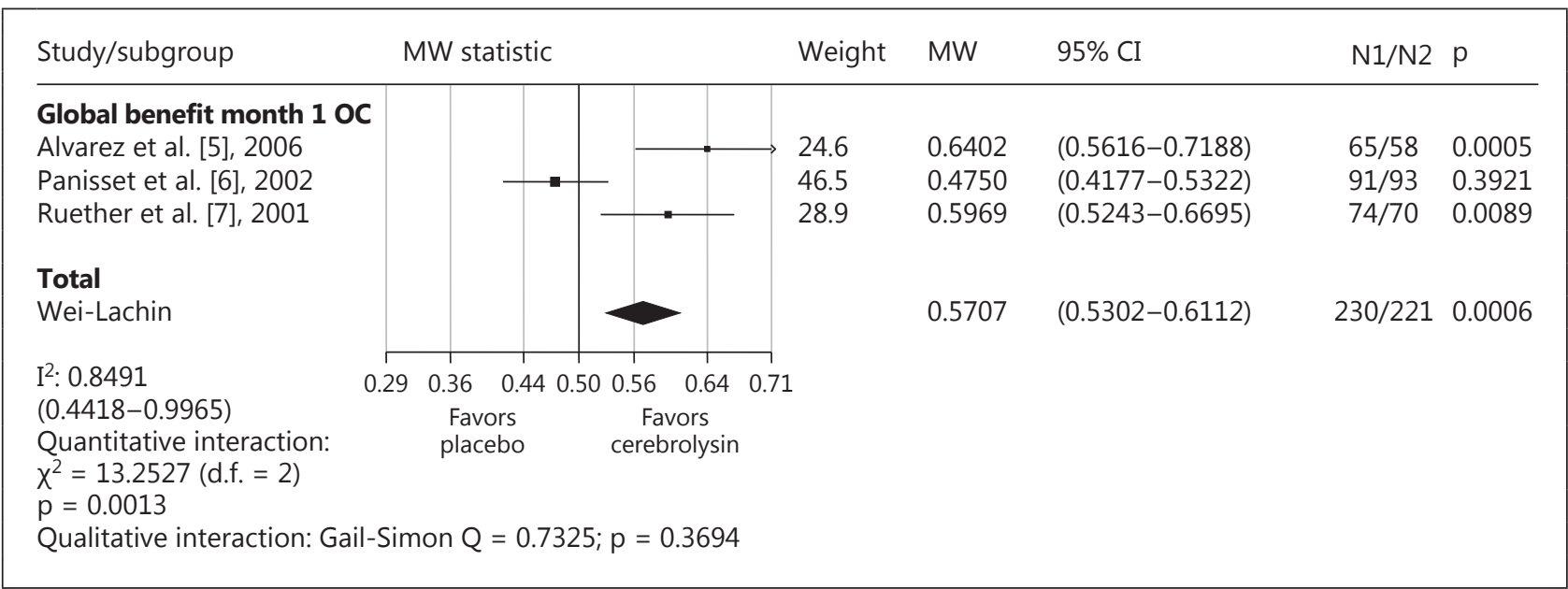

Fig. 5. Comparison of Cerebrolysin (30 ml/day) versus placebo at week 4, global benefit: combined global clinical change plus primary cognitive outcome measures (multivariate), effect size: MW, OC.

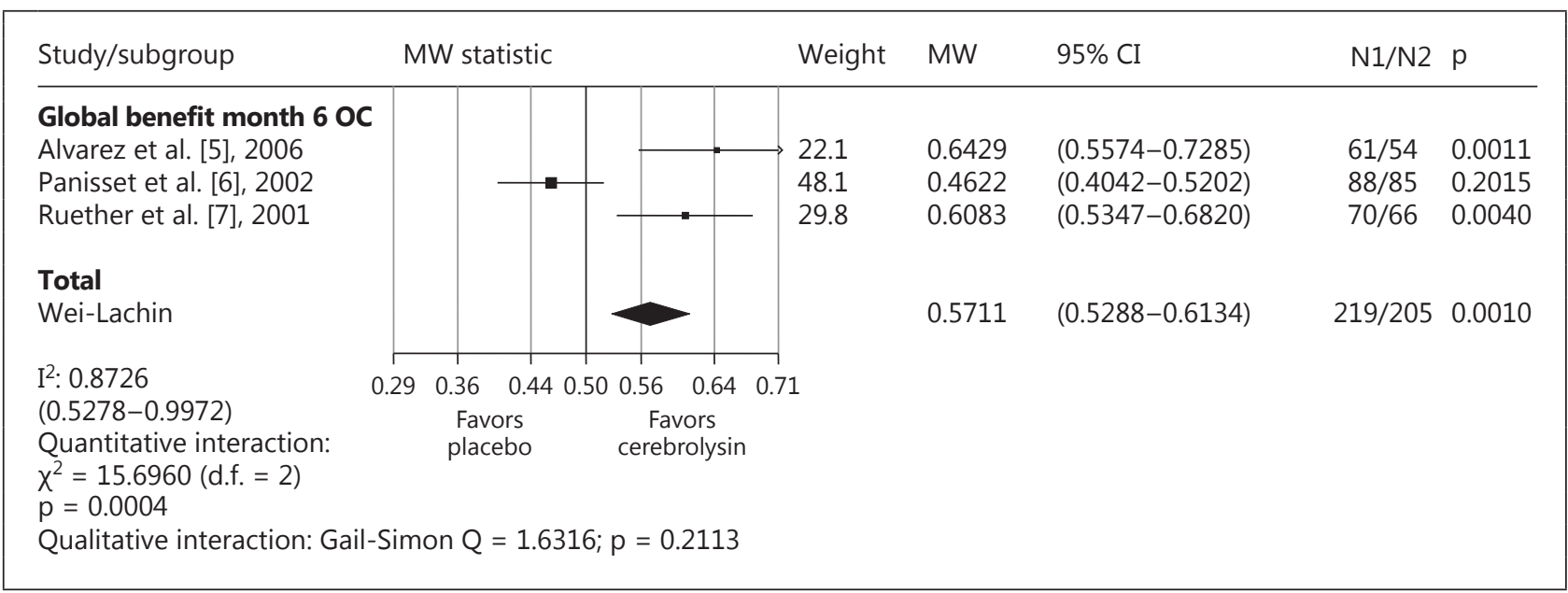

Fig. 6. Comparison of Cerebrolysin ( $30 \mathrm{ml} /$ day) versus placebo at month 6 , global benefit: combined global clinical change plus primary cognitive outcome measures (multivariate), effect size: MW, OC.

analysis confirmed the results of the OC analysis (all $p<0.01$ ). Two [5, 7] of the 3 included studies show also stand-alone significance regarding the combined efficacy criteria $(\mathrm{p}=$ 0.0005 and 0.0089 at week $4 ; p=0.0011$ and 0.0040 at month 6), while for 1 study [6] results were statistically not significant (see also remarks in the Limitations section).

\section{Safety and Tolerability}

For 4-week studies, incidence rates were highly zero-dominated due to the short observation time, thus preventing reasonable safety conclusions based on OR. Thus, safety and tolerability aspects based on meta-analyses of OR will be discussed for 6-month studies with IPD only [5-7]. More Cerebrolysin-treated patients than placebo-treated patients completed the 6-month studies (93.4 vs. 89.6\%). The overall rates of premature discontinuation for any reason (fig. 7) were $6.6 \%$ for the Cerebrolysin patients and $10.4 \%$ for the placebo patients, 
Dementia

Cognitive Disorders
Dement Geriatr Cogn Disord 2015;39:332-347

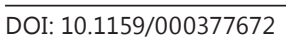

Gauthier et al.: Cerebrolysin in Mild-to-Moderate Alzheimer's Disease: A Meta-Analysis of Randomized Controlled Clinical Trials

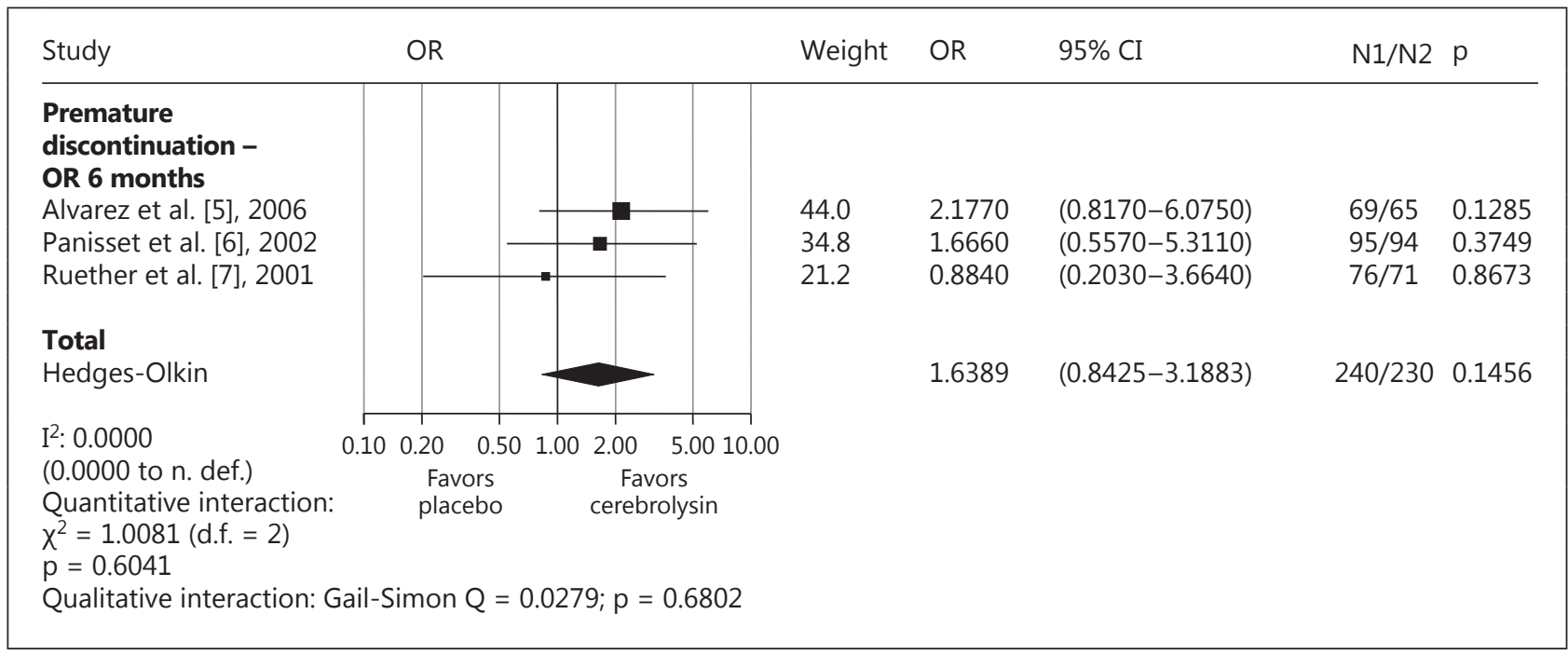

Fig. 7. Comparison of Cerebrolysin (30 ml/day) versus placebo, premature discontinuation, effect size: OR, OC.

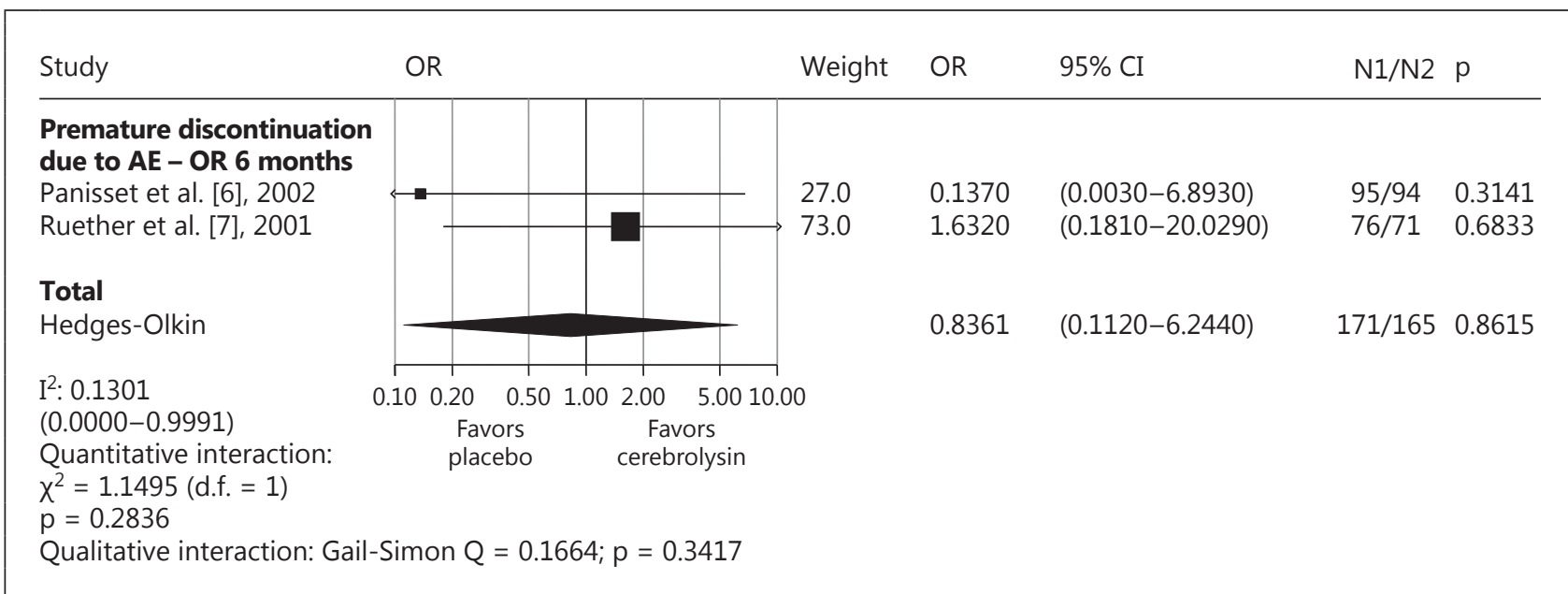

Fig. 8. Comparison of Cerebrolysin ( $30 \mathrm{ml} /$ day) versus placebo, premature discontinuation due to AE, effect size: $\mathrm{OR}^{\mathrm{a}}$, OC. ${ }^{\text {a }}$ The study by Alvarez et al. [5] was excluded from this analysis due to zero events in both groups.

which resulted in an OR of 1.64 in favor of Cerebrolysin. For discontinuations due to AEs (fig. 8), the incidences for Cerebrolysin and placebo patients were very similar (OR 0.84). The overall incidence of TEAEs with Cerebrolysin (fig. 9) did not differ from that with placebo (33.8 vs. $34.9 \%$ for Cerebrolysin vs. placebo; OR 1.2), and most AEs were mild to moderate in severity. The most frequently occurring AEs, with a higher incidence in the Cerebrolysin group than in the placebo group, were headache (13.8 vs. $12.2 \%$ for Cerebrolysin vs. placebo, respectively), vertigo (10.8 vs. 9.1\%), and hyperhidrosis (7.9 vs. 7.4\%). The incidence of serious AEs (SAEs) was slightly higher in the Cerebrolysin group as compared with the placebo group (4.2 vs. 3.8\%, OR 0.86), and the majority of SAEs were considered to be unrelated to the study medication. 


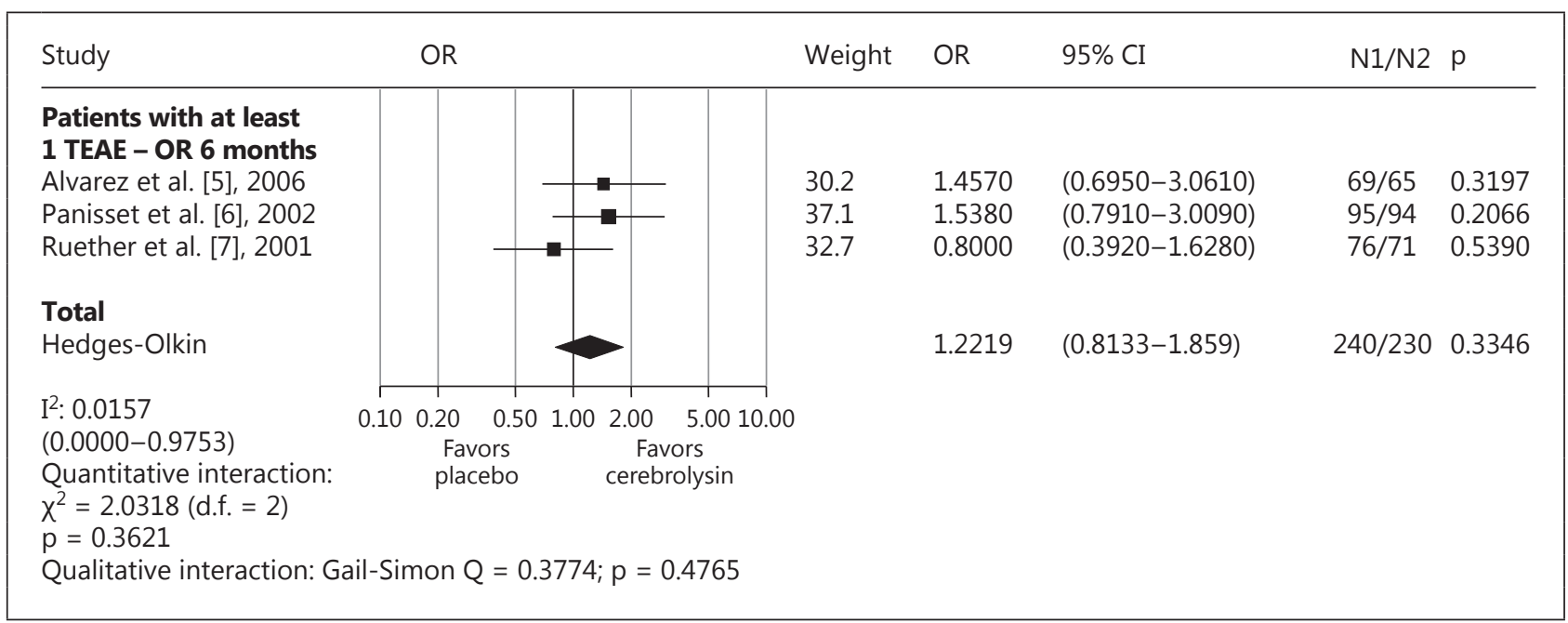

Fig. 9. Comparison of Cerebrolysin ( $30 \mathrm{ml} /$ day) versus placebo, patients with at least $1 \mathrm{TEAE}$, effect size: $\mathrm{OR}$, OC.

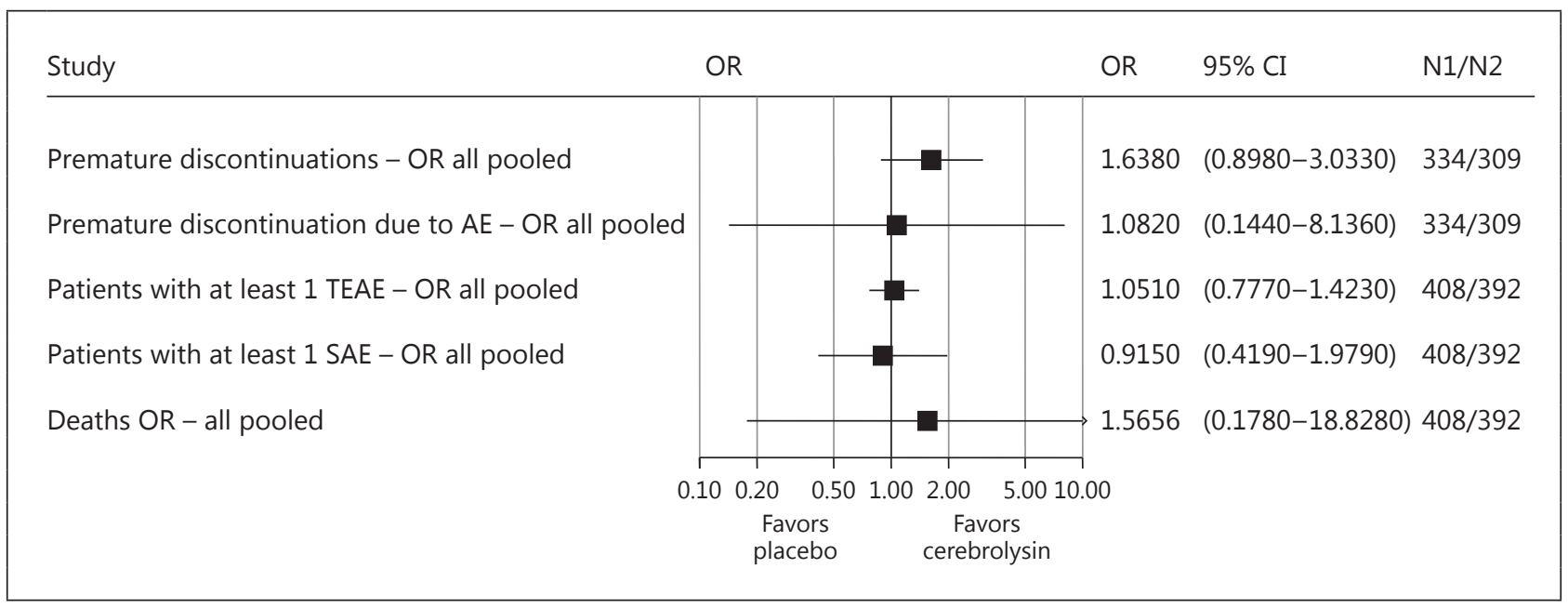

Fig. 10. Comparison of Cerebrolysin ( $30 \mathrm{ml} /$ day) versus placebo, various safety criteria, crude pooling, effect size: OR, OC.

Several regulatory authorities recommend an additional crude pooling procedure for safety events, since then, also studies with zero safety events can be included into the summarizing statistics. ORs based on the crude pooling procedure including all 6 studies are shown in figure 10, supporting the findings of the formal IPD meta-analyses (premature discontinuation: $\mathrm{OR}=1.6380$; premature discontinuation due to $\mathrm{AE}: \mathrm{OR}=1.0820$; patients with at least 1 TEAE: $\mathrm{OR}=1.0510$; patients with at least $1 \mathrm{SAE}: \mathrm{OR}=0.9150$; deaths: $\mathrm{OR}=1.5656$ ).

\section{Limitations}

While the tests for qualitative interaction suggest that corresponding variations of the study results are compatible with chance alone, the tests for quantitative interaction suggest some heterogeneity regarding the size of the effects in the individual studies. Meta-analyses consistently show larger effect sizes in favor of Cerebrolysin when applying a random-effects 
Dementia

Cognitive Disorders

\begin{tabular}{l|l}
\hline Dement Geriatr Cogn Disord 2015;39:332-347 \\
\hline DOI: 10.1159/000377672 & $\begin{array}{l}\text { (c) 2015 S. Karger AG, Basel } \\
\text { www.karger.com/dem }\end{array}$ \\
\hline
\end{tabular}

Gauthier et al.: Cerebrolysin in Mild-to-Moderate Alzheimer's Disease: A Meta-Analysis of Randomized Controlled Clinical Trials

model (DerSimonian-Laird) instead of a fixed-effects model (Hedges-Olkin). Thus, the fixedeffects analysis seems to be the more conservative approach regarding the estimation of the true size of the effects; this applies to all efficacy results (e.g. global clinical change at week 4: $\mathrm{I}^{2}=0.9083, \mathrm{p}<0.0001 ; \mathrm{OR}_{\text {fixed-effects }}=2.8819, \mathrm{OR}_{\text {random-effects }}=3.3197 ;$ month $6: \mathrm{I}^{2}=0.8735$, $\mathrm{p}<0.0001 ; \mathrm{OR}_{\text {fixed-effects }}=3.0840, \mathrm{OR}_{\text {random-effects }}=4.9771$; both approaches show a significant treatment effect at both points in time). It is interesting to note that 1 [6] of the 6 studies shows a more or less consistent deviation of effect sizes as compared to the other 5 studies, with partly reversed effects. The identifiable differences from the other 5 studies were as follows: the study is the only non-European study (Canadian centers); it is the study with the largest number of small centers, and the known correlation between cognitive scales and global clinical change in patients with AD partly failed or was even reversed in this study (Pearson $r=-0.0738$ at week 4 as compared to, for example, Pearson $r=0.5787$ [5], which is the expected correlation in an $\mathrm{AD}$ population). However, no hints were found in the reported data of the study which might explain this unusual behavior; also, no medical reasons or deviating population characteristics could be identified as possible explanations. After excluding the outlier study, patients with AD showed markedly larger effect sizes as compared to the results presented in figures 1-4 (global clinical change at month 6: $\mathrm{OR}_{\text {random-effects }}=8.6695$ as compared to $4.9771, \mathrm{p}=0.0067$ ). The outstanding effect of Cerebrolysin in 1 of the studies [15] on the global impression might be due to the milder form of the disease in this patient population as compared to the other studies. In most of the placebo patients, the condition was unchanged, whereas most of the Cerebrolysin patients improved, which is in line with the fast onset of action of Cerebrolysin and the sustained treatment effect. A sensitivity analysis excluding both studies $[6,15]$ still showed statistical significance for global clinical change at month 6 in the fixed-effects model ( $p<0.0001)$ as well as in the random-effects model $(p=0.0037)$.

\section{Discussion}

This meta-analysis comprised results of 6 individual double-blind placebo-controlled studies of Cerebrolysin in patients with mild-to-moderate AD. Cerebrolysin treatment resulted in a statistically significant benefit in the two main efficacy domains suggested by the FDA as of primary interest: the cognitive and global endpoint [21]. As the focus of this metaanalysis was on the primary outcome measures and all of the included studies defined cognitive function and global assessment of change as primary outcome measures, the effects of Cerebrolysin on functioning and behavior measures were not included in this meta-analysis (in addition, high heterogeneity of secondary scales and incomplete reporting of required statistics made corresponding meta-analyses questionable or impossible). The 6 studies in this meta-analysis had a similar design and all were placebo-controlled, double-blind, and parallel-group trials, with a double-blind treatment period of at least 4 weeks. Patients in the studies were randomly assigned to either placebo or active treatment, and treatment arms were equally balanced with regard to age, gender, etc. The standardized effect size of Cerebrolysin on the cognitive domain in the present analysis (SMD -0.37, OC, month 6) was comparable to the range seen for other antidementia treatments [18, 20, 39-42]. The effect size of Cerebrolysin on the global domain (OR 4.98), as assessed by the CIBIC+ instrument (by itself a measure of clinical relevance) or CGI, supported the clinical importance of this cognitive benefit. The LOCF analysis resulted in similar overall effect sizes.

\section{Verification of Results in Original Publications}

One of the major advantages of using IPD for a meta-analysis is the possibility to verify results presented in the original study publications (assuming IPD provided can be matched 


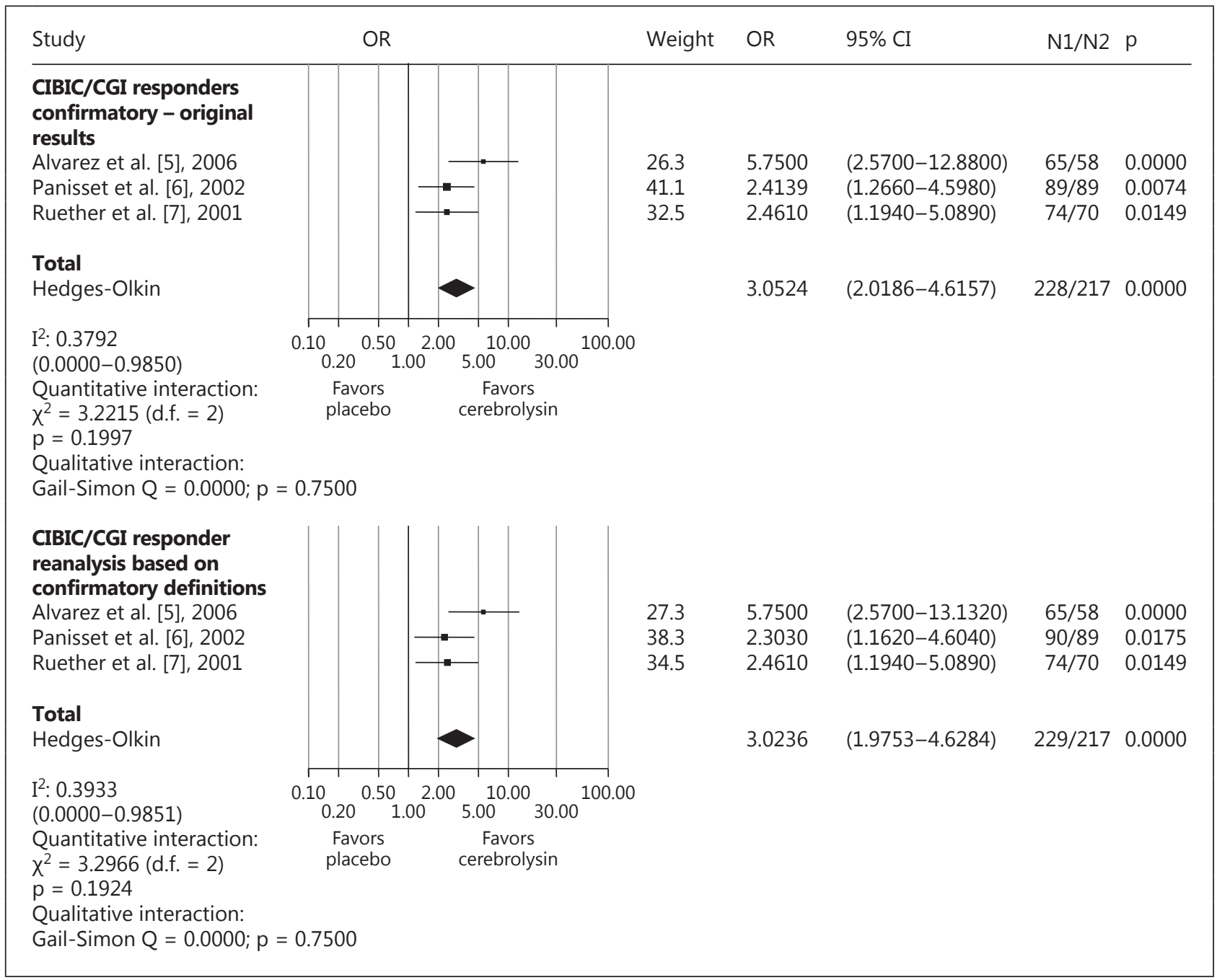

Fig. 11. Comparison of Cerebrolysin ( $30 \mathrm{ml} /$ day) versus placebo, global clinical change, primary points in time, effect size: OR, aggregate data meta-analysis versus IPD meta-analysis.

to the IPD used in the original analyses). For validation purposes, the results of the global clinical change based on the IPD reanalysis have been compared with a meta-analysis based on the originally reported confirmatory results. For this purpose, the definitions of the original investigational plans were applied to both analyses (primary point in time, cutoff point for dichotomization, and method of baseline adjustment). Figure 11 shows the comparison for the global clinical change based on the 3 studies with available raw data (IPD studies [5-7]). The two ORs indicate perfect agreement (OR 3.05 vs. 3.02). This result is also in line with the global clinical change result including all 6-month studies in the mixed meta-analysis (OR 3.1, see fig. 4). The ADAS-cog validation resulted in similar overall agreement of effect sizes, thus suggesting consistency of the results.

\section{Benefit-Risk Relation}

There is a positive benefit-risk relation in favor of Cerebrolysin with an NNT for benefit with respect to the 6-month global clinical change of 2.9 as compared to the lowest calculated 
Gauthier et al.: Cerebrolysin in Mild-to-Moderate Alzheimer's Disease: A Meta-Analysis of Randomized Controlled Clinical Trials

NNT for harm with respect to risk of 501 ('patients with premature discontinuation due to $\mathrm{AE}^{\prime}$ ). Regarding the multivariate result after 6 months (combined cognitive function and global clinical change), the NNT for benefit was 7.0 (NNT derived from Mann-Whitney estimator by means of the procedure according to Kraemer et al. [43]).

\section{Comparison to a Previous Meta-Analysis}

A previous meta-analysis of Cerebrolysin in mild-to-moderate AD [44], based on aggregate data, showed serious shortcomings: ADAS-cog effect sizes of 2 included studies were incorrect $(0.92$ instead of $-0.84,-4.10$ instead of -3.63$)$, and there was significant heterogeneity for 3 of the 4 outcomes. However, potential sources of heterogeneity were not investigated. Shortand long-term results were mixed in the same meta-analysis, and it was not reported whether the data used in the analysis were after treatment or at the end of the follow-up period. Handling of missing data and responder definitions were inconsistent across studies. Thus, there was a rationale for a fresh, updated meta-analysis avoiding previous drawbacks.

\section{Summary}

The meta-analysis results of 6 randomized placebo-controlled trials demonstrate beneficial effect of Cerebrolysin compared to placebo on the global clinical state and cognitive function at week 4 and month 6 . The global clinical change showed statistical significance in the short-term analysis (after 4 weeks of treatment) as well as for the long-term follow-up after 6 months. This applies to the OC analysis as well as to the LOCF sensitivity analysis.

The meta-analysis of cognitive data reproduced the results obtained with the global clinical change for the short-term analysis. For the long-term analysis, a comparable effect size was observed, but it missed statistical significance. The meta-analysis of global benefit (multivariate analysis combining global clinical change and cognitive function) shows a statistically significant advantage of Cerebrolysin as compared to placebo at all points in time, in the OC analysis as well as in the alternative LOCF analysis ( $\mathrm{p} \leq 0.01)$. The NNT showed a significant global benefit after 1 month (OC: generalized NNT $=7.1$ ) as well as after 6 months (OC: generalized NNT $=7.0$ ).

With respect to safety aspects, negligible differences varying around the benchmark for equality were found regarding premature discontinuations due to $\mathrm{AE}$, patients with at least $1 \mathrm{TEAE}$, and patients with at least $1 \mathrm{SAE}$ (crude pooling of all studies). The rate of overall premature discontinuations was slightly lower in the Cerebrolysin group.

\section{Conclusion}

This meta-analysis provides evidence that Cerebrolysin has an overall beneficial effect on cognitive function and global clinical change in patients with mild-to-moderate AD. The safety aspects of Cerebrolysin were comparable to placebo, thus suggesting a favorable benefit-risk ratio.

When comparing the findings of this meta-analysis with those of donepezil [45] or memantine [46] at 6 months, Cerebrolysin can be placed with its effects on cognitive function (SMD $=0.29$ in fixed-effects model; SMD $=0.37$ in random-effects model) between the smaller effect sizes of memantine (SMD $=0.14$ ) and the higher effect sizes of $10 \mathrm{mg}$ donepezil $(\mathrm{SMD}=0.5)$. Evaluating the benefit-risk relation as compared to donepezil, it has to be con- 
Gauthier et al.: Cerebrolysin in Mild-to-Moderate Alzheimer's Disease: A Meta-Analysis of Randomized Controlled Clinical Trials

sidered that there were no safety concerns at all with respect to Cerebrolysin, while for $10 \mathrm{mg}$ donepezil, significant safety findings were reported in the Cochrane meta-analyses.

There is still a need for further research to evaluate the effects of Cerebrolysin on cognitive performance and activities of daily living in various dementias. Clinicians should consider Cerebrolysin as a therapeutic agent when seeking more treatment options for mild-tomoderate AD, as it may also be combined with standard registered drugs, e.g. acetylcholinesterase inhibitors.

\section{Disclosure Statement}

S. Gauthier is a member of the EVER scientific advisory board. No honoraria were received for the writing of this article. J.V. Proaño has no work-related relationship with EVER and has never received any honorarium or other form of compensation for any work previous to or during the writing of this article. J. Jia has no potential conflicts of interest or disclosures relevant to this article. L. Froelich has received honoraria or consulting fees for working with Axon Neuroscience, Boehringer Ingelheim, Eisai, Eli Lilly, GE Health Care, Lundbeck, Merck Sharpe and Dohme, Merz Pharma, Novartis, Nutricia, Otsuka, Pfizer, Roche, SanofiAventis, and Schering-Plough. J.C. Vester is senior biometric consultant of idv, a member of the International Scientific Committee of the Society for the Study of Neuroprotection and Neuroplasticity (SSNN), a member of the EVER scientific advisory board, and will be trial statistician of the next RCT with Cerebrolysin. No honorarium has been received for the writing of this article. E. Doppler is employee of EVER Neuro Pharma GmbH.

\section{References}

1 Álvarez XA, Fuentes P: Cerebrolysin in Alzheimer's disease. Drugs Today (Barc) 2011;47:487-513.

2 Plosker GL, Gauthier S: Spotlight on Cerebrolysin in dementia. CNS Drugs 2010;24:263-266.

3 Young W: Cerebrolysin review. Originally posted April 1, 2006 (minor revisions February 10, 2009). https:// wiseyoung.wordpress.com/2009/02/10/271/.

4 Fragoso YD, Dantas DC: Cerebrolysin for Alzheimer's disease. Cochrane Database Syst Rev 2002;3:CD003801.

5 Alvarez XA, Cacabelos R, Laredo M, Couceiro V, Sampedro C, Varela M, et al: A 24-week, double-blind, placebocontrolled study of three dosages of Cerebrolysin in patients with mild to moderate Alzheimer's disease. Eur J Neurol 2006;13:46-54.

6 Panisset M, Gauthier S, Moessler H, Windisch M: Cerebrolysin in Alzheimer's disease: a randomized, doubleblind, placebo-controlled trial with a neurotrophic agent. J Neural Transm 2002;109:1089-1104.

7 Ruether E, Husmann R, Kinzler E, Diabl E, Klingler D, Spatt J, et al: A 28-week, double-blind, placebo-controlled study with Cerebrolysin in patients with mild to moderate Alzheimer's disease. Int Clin Psychopharmacol 2001;16:253-263.

8 Riley RD, Lambert PC, Abo-Zaid G: Meta-analysis of individual participant data: rationale, conduct, and reporting. BMJ 2010;340:c221.

9 Rosen WG, Mohs RC, Davis KL: A new rating scale for Alzheimer's disease. Am J Psychiatry 1984;141:13561364.

10 Mohs RC, Knopman D, Petersen RC, Ferris SH, Ernesto C, Grundman M, et al: Development of cognitive instruments for use in clinical trials of antidementia drugs: additions to the Alzheimer's Disease Assessment Scale that broaden its scope. The Alzheimer's Disease Cooperative Study. Alzheimer Dis Assoc Disord 1997;11: 13-21.

11 Folstein MF, Folstein SE, McHugh PR: 'Mini-mental state'. A practical method for grading the state of patients for the clinician. J Psychiatr Res 1975;12:189-198.

12 Oswald WD, Fleischmann UM: Das Nürnberger-Alters-Inventar NAI. Göttingen, Hogrefe, 1986.

13 Knopman DS, Knap MJ, Gracon SI, Davis CS: The Clinician Interview-Based Impression (CIBI): a clinician's global change rating scale in Alzheimer's disease. Neurology 1994;44:2315-2321.

14 Guy W: 028 CGI: Clinical global impressions; in Guy W (ed): ECDEU Assessment Manual for Psychopharmacology, Revised. National Institute of Mental Health, Rockville, 1976, pp 217-222.

15 Ruether E, Ritter R, Apecechea M, Freytag S, Windisch M: Efficacy of the peptidergic nootropic drug Cerebrolysin in patients with senile dementia of the Alzheimer type (SDAT). Pharmacopsychiatry 1994;27:32-40.

16 Bae CY, Cho CY, Cho K, Hoon Oh B, Choi KG, Lee HS, et al: A double-blind, placebo-controlled, multicenter study of Cerebrolysin for Alzheimer's disease. J Am Geriatr Soc 2000;48:1566-1571.

17 Xiao SF, Yan HQ, Yao PF; Cerebrolysin Study Group: Efficacy of FPF 1070 (Cerebrolysin) in patients with Alzheimer's disease. Clin Drug Investig 2000;19:43-53. 
Gauthier et al.: Cerebrolysin in Mild-to-Moderate Alzheimer's Disease: A Meta-Analysis of Randomized Controlled Clinical Trials

18 Birks JS, Harvey R: Donepezil for dementia due to Alzheimer's disease. Cochrane Database Syst Rev 2003; 3:CD001190.

19 Cochrane Handbook for Systematic Reviews of Interventions. Version 5.1.0. (updated March 2011). The Cochrane Collaboration, 2011.

20 IQWIG, Institut für Qualität und Wirtschaftlichkeit im Gesundheitswesen: Cholinesterasehemmer bei Alzheimer Demenz. Abschlussbericht A05-19A. IQWIG, Köln, 2007.

21 Katz R: FDA: evidentiary standards for drug development and approval. NeuroRx 2004;1:307-316.

22 Wei LJ, Lachin JM: Two-sample asymptotically distribution-free tests for incomplete multivariate observations. J Am Stat Assoc 1984;79:653-661.

23 Lachin JM: Some large-sample distribution-free estimators and tests for multivariate partially incomplete data from two populations. Stat Med 1992;11:1151-1170.

24 Dmitrienko A, Tamhane AC, Bretz F (eds): Multiple Testing Problems in Pharmaceutical Statistics. Boca Raton, Chapman and Hall/CRC, 2010.

25 Laupacis A, Sackett DL, Roberts RS: An assessment of clinically useful measures of the consequences of treatment. N Engl J Med 1988;318:1728-1733.

26 Cook RJ, Sackett DL: The number needed to treat: a clinically useful measure of effect. BMJ 1995;310:452-454.

27 Altman DG: Confidence intervals for the number needed to treat. BMJ 1998;317:1309-1312.

28 Guyatt GH, Juniper EF, Walter SD, Griffith LE, Goldstein RS: Interpreting treatment effects in randomised trials. BMJ 1998;316:690-693.

29 Walter SD: Number needed to treat (NNT): estimation of a measure of clinical benefit. Stat Med 2001;20: 3947-3962.

30 Altman DG, Andersen PK: Calculating the number needed to treat where the outcome is time to an event. BMJ 1999;319:1492-1495.

31 Altman DG, Schulz KF, Moher D, Egger M, Davidoff F, Elbourne D, et al: The revised CONSORT statement for reporting randomized trials: explanation and elaboration. Ann Intern Med 2001;134:663-694.

32 Schulz KF, Altman DG, Moher D; CONSORT Group: CONSORT 2010 statement: updated guidelines for reporting parallel group randomised trials. BMC Med 2010;8:18.

33 Gail M, Simon R: Testing for qualitative interactions between treatment effects and patient subsets. Biometrics 1985;41:361-372.

34 DerSimonian R, Laird N: Meta-analysis in clinical trials. Control Clin Trials 1986;7:177-188.

35 Chang B, Lowenstein D: Report of the Quality Standards Subcommittee of the American Academy of Neurology, Appendix I: Definitions for classification of evidence. Neurology 2003;60:10-16.

36 Liberati A, Altman DG, Tetzlaff J, Mulrow C, Gotzsche PC, Ioannidis JPA: The PRISMA statement for reporting systematic reviews and meta-analyses of studies that evaluate healthcare interventions: explanation and elaboration. BMJ 2009;339:b2700.

37 Colditz GA, Miller JN, Mosteller F: Measuring gain in the evaluation of medical technology. The probability of a better outcome. Int J Technol Assess Health Care 1988;4:637-642.

38 Lachin JM: Biostatistical Methods: The Assessment of Relative Risks. New York, John Wiley and Sons, 2000.

39 Birks J, Grimley Evans J, Iakovidou V, et al: Rivastigmine for Alzheimer's disease. Cochrane Database Syst Rev 2009;2:CD001191.

40 Loy C, Schneider L: Galantamine for Alzheimer's disease and mild cognitive impairment. Cochrane Database Syst Rev 2006;1:CD001747.

41 Areosa SA, Sherriff F: Memantine for dementia. Cochrane Database Syst Rev 2003;3:CD0033154.

42 Doody RS, Tariot PN, Pfeiffer E, Olin JT, Graham SM: Meta-analysis of six-month memantine trials in Alzheimer's disease. Alzheimers Dement 2007;3:7-17.

43 Kraemer HC, Morgan GA, Leech NL, Gliner JA, Vaske JJ, Harmon RJ: Measures of clinical significance. J Am Acad Child Adolesc Psychiatry 2003;42:1524-1529.

44 Wei ZH, He QB, Wang H, Su BH, Chen HZ: Meta-analysis: the efficacy of nootropic agent Cerebrolysin in the treatment of Alzheimer's disease. J Neural Transm 2007;114:629-634.

45 Birks J, Harvey RJ: Donepezil for dementia due to Alzheimer's disease. Cochrane Database Syst Rev 2006; 1:CD001190.

46 McShane R, Areosa SA, Minakaran N: Memantine for dementia. Cochrane Database Syst Rev 2006;2:CD003154. 